\title{
CAUSES AND PRESENTATION OF CERVICAL LYMPHADENOPATHY
}

\author{
Arifullah¹, Waqar U Din², Syed Zafar Hassan ${ }^{3}$, Ghulam Muhammad ${ }^{4}$
}

1. Town Teaching Hospital

\section{ABSTRACT}

\section{OBJECTNE}

To determine the proportion of cervical lymphadenopathy in systemic diseases, their presentation and investigative tools.

\section{METHODOLOGY}

This descriptive study was carried out from $1^{\text {st }}$ July 2014 to 30 June 2017 in ENT and head and neck department Naseer Teaching Hospital and Town Teaching Hospital, Peshawar. Total of 270 patients with enlarged cervical lymph nodes, of either sex and of any age were approached for inclusion into the study. Patients with suspected acute inflammation were given a trial of antibiotic and followed for two weeks were excluded from the study. Excisional biopsy of the lymph nodes was performed in all these patients with six weeks or more duration.

\section{RESULTS}

In our study out of 270 patients, 158 (58.5\%) were males and the majority of patients (63.3\%) had ages from 11-40 years. Tuberculous cervical lymphadenopathy was diagnosed in 145 (53.7\%) patients, reactive hyperplasia in 53 (19.6\%), lymphoma in $32(11.8 \%$,) metastasis to cervicallymph nodes in $30(11.1 \%)$, sarcoidosis in $7(2.6 \%)$ and other very rare conditions as Kawasaki, Kikuchie and Rosi Dorfman were found in only one of each (0.4\%). About 136 (50.4\%) of the patients had involvement of multiple lymph nodes while 134 (49.6\%) had single swelling. The matted lymph nodes were found in 162 (60\%) whereas discretelymph nodes were found in only $108(40 \%)$ cases. Cold abscess was found in 19 (7\%) of patients.

\section{CONCLUSION}

Tuberculosis is the commonest cause of cervical lymphadenopathy, with the majority of these patients having multiple lymph node involvement. In children, usually cervical lymphadenopathy is reactive or infective while in older age mostly metastatic.

KEY WORDS: Cervical lymphadenopathy, Excisional biopsy of lymph nodes

\section{INTRODUCTION}

The term lymphadenopathy refers to the enlargement of the lymph nodes, either due to the disease of lymph nodes or secondary to the systemic diseases. The size of cervical lymph node less than $1 \mathrm{~cm}$ in diameter is generally considered to be normal. Different causes of cervical lymphadenopathy include infections, inflammatory diseases, degenerative diseases and neoplasms. ${ }^{1}$

Infectious/inflammatory causes of cervical lymphadenopathy are mainly tuberculosis, cat-scratch disease, syphilis, leprosy, actinomycosis, rhinoscleroma, and fungal infections. Granulomatosis

Correspondence:

Dr. Arifullah Bangash

Tow $n$ Teaching Hospital

Contact: 0302-5563

Email: drmrf@hotmail.com

https://doi.org/10.37762/iamds.4-2.21

intracellular Toxoplasma gondii. ${ }^{3}$

The diagnosis of cervical lymphadenopathy is mainly based on careful history and physical examination followed by different tools of investigation. The age of the patient gives clear clue in diagnosis of cervical lymphadenopathy, usually cervical lymphadenopathy in children is reactive or 
infective while in older age mostly metastatic cervical lymphadenopathy noted. ${ }^{4}$ Physical findings of enlarge lymph nodes like tenderness and fluctuations are important clues of infective diseases while hard and fixed lymph nodes indicate malignant process. In lymphoma, usually there are multiple enlarged nodes which feel rubbery to palpation. Constitutional symptoms such as fever, weight loss, fatigue or night sweats could suggest disorders such as tuberculos is, lymphoma, collagen vascular diseases, unrecognized infection or malignancy. The presence of fever is commonly associated with infections. ${ }^{5}$ Cold abscess is a clinical feature of tuberculosis. ${ }^{6}$

The list of important investigative tools used to reach to the conclusion of cervical lymphadenopathy are ultrasound, FNAC, CT scan/MRI and excisional biopsy. Ultra sound is an excellent first line investigating tool for enlarged lymph nodes,using Grey ultrasound scale and avoids invasive procedures. ${ }^{7}$ Fine needle aspiration cytology is minimal invasive procedure usually used to diagnose the cervical lymphadenopathy. To confirm the histopathological diagnosis, an excision biopsy is performed on the palpable and largest and easily excisable lymph nodes. ${ }^{8}$ Computed tomography (CT) of the neck, chest, abdomen and pelvis is the most appropriate initial investigation following FNAC diagnosis of metastatic adenocarcinoma in cervical lymph nodes with unknown primary. ${ }^{9}$

\section{METHODOLOGY}

This descriptive study was undertaken from $1^{\text {st }}$ July 2014 to 30 June 2017 in ENT and head and neck department Naseer Teaching Hospital and Town Teaching Hospital, Peshawar. Total of 270 patients with enlarged cervical lymph nodes, of either sex and of any age were approached for inclusion into the study. Patients with suspected acute inflammation were given a trial of antibiotic and followed for two weeks were excluded from the study. Excisional biopsy of the lymph nodes was performed in all these patients with six weeks or more duration. Written informed consent for recruitment into the study was obtained from all patients.

Detailed history and physical examination were performed as part of routine clinical care. Lymph nodes were examined for site, size, number, whether matted or discrete, presence of tenderness, consistency, and their relation to underlying structures. Relevant investigations were carried out in all cases including screening for Hepatitis B and Hepatitis C infection, complete blood picture, erythrocyte sedimentation rate (ESR) and chest x-ray. Excision biopsy was performed.

Statistical analysis was done using SPSS version 12.

\section{RESULTS}

Out of 270 patients, 186 (68.9\%) were males and the majority of patients had ages from 12-40 years. Tuberculous cervical lymphadenopathy was diagnosed in 141 (74.5\%) patients, reactive hyperplasia in $30(11.1 \%)$, metastasis to cervical lymph nodes in $18(6.7 \%)$, lymphoma in $12(4.4 \%)$ and Kikuchie's lymphadenitis in $9(3.3 \%)$ cases. About $146(80 \%)$ of the patients had involvement of multiple lymph nodes while $36(20 \%)$ had single swelling. $189(70 \%)$ of the patients had matted lymph nodes whereas discrete lymph nodes were found in only $36(20 \%)$ cases.

A single lymph node group was involved in 54 (60\%) patients and more than 2 lymph node groups were involved in $11(12.2 \%)$ patients. In 61 (67.8\%) cases, there were matted lymph nodes, whereas $16(17.8 \%)$ of the patients were having discrete lymph nodes.

The posterior triangle (level V) was the most common site of lymphadenopathy in $45(50 \%)$ patients, followed by upper deep cervical (level II) in $28(31.1 \%)$ and submandibular region (level I) in 8 $(8.9 \%)$ patients. Cold abscesses were present in $7 \%$ as shown in table 2.

Tuberculous cervical lymphadenopthy was the most common histological diagnosis in 141/270 $(52.2 \%)$ patients followed by reactive hyperplasia in 50/270 (18.5\%), lymphoma 33/270 (12.2\%), metastatic 29/270 (10.7\%), other rare diseases like Kawasaki disease, Rosi Dorfman and Kikuchie's were found in 1/270 (0.4\%) each as shown in table 3. 
Table;1, Demographic presentation

\begin{tabular}{|l|c|c|}
\hline \multicolumn{1}{|c|}{ Characteristics } & Number of patients & Percentage \\
\hline Male & $158 / 270$ & $58.5 \%$ \\
Female & $112 / 270$ & $41.5 \%$ \\
\hline Less than 10 years & $47 / 270$ & $17.4 \%$ \\
$11-40$ years & $171 / 270$ & $63.3 \%$ \\
More than 40 years & $52 / 270$ & $19.3 \%$ \\
\hline Single lymph node group & $134 / 270$ & $50.4 \%$ \\
Multiple lymph node groups & $136 / 270$ & $49.6 \%$ \\
\hline Matted lymph nodes & $162 / 270$ & $60 \%$ \\
Discrete lymph nodes & $108 / 270$ & $40 \%$ \\
\hline
\end{tabular}

Table 2; Involvement of lymph node groups and abscess

\begin{tabular}{|l|c|c|}
\hline \multicolumn{1}{|c|}{ Node groups/abscess } & Number of patients & Percentage \\
\hline Posterior triangle nodes & $131 / 270$ & $48.5 \%$ \\
\hline Upper deep cervical nodes & $97 / 270$ & $35.9 \%$ \\
\hline Submandibular nodes & $25 / 270$ & $9.3 \%$ \\
\hline Pretracheal & $17 / 270$ & $6.3 \%$ \\
\hline Cold abscess & $19 / 270$ & $7 \%$ \\
\hline
\end{tabular}

Table 3: Etiology of cervical lymphadenopathy

\begin{tabular}{|l|c|c|}
\hline \multicolumn{1}{|c|}{ Causes } & Number of patients & Percentage \\
\hline Tuberculosis & $145 / 270$ & $53.7 \%$ \\
\hline Reactive & $53 / 270$ & $19.6 \%$ \\
\hline Lymphoma & $32 / 270$ & $11.8 \%$ \\
\hline Metastatic & $30 / 270$ & $11.1 \%$ \\
\hline Sarcoidosis & $7 / 270$ & $2.6 \%$ \\
\hline Kickuchie's disease & $1 / 270$ & $0.4 \%$ \\
\hline Rrosi dorfman & $1 / 270$ & $0.4 \%$ \\
\hline Kawasaki disease & $1 / 270$ & $0.4 \%$ \\
\hline
\end{tabular}

Figure 1; levels of cervical lymph nodes

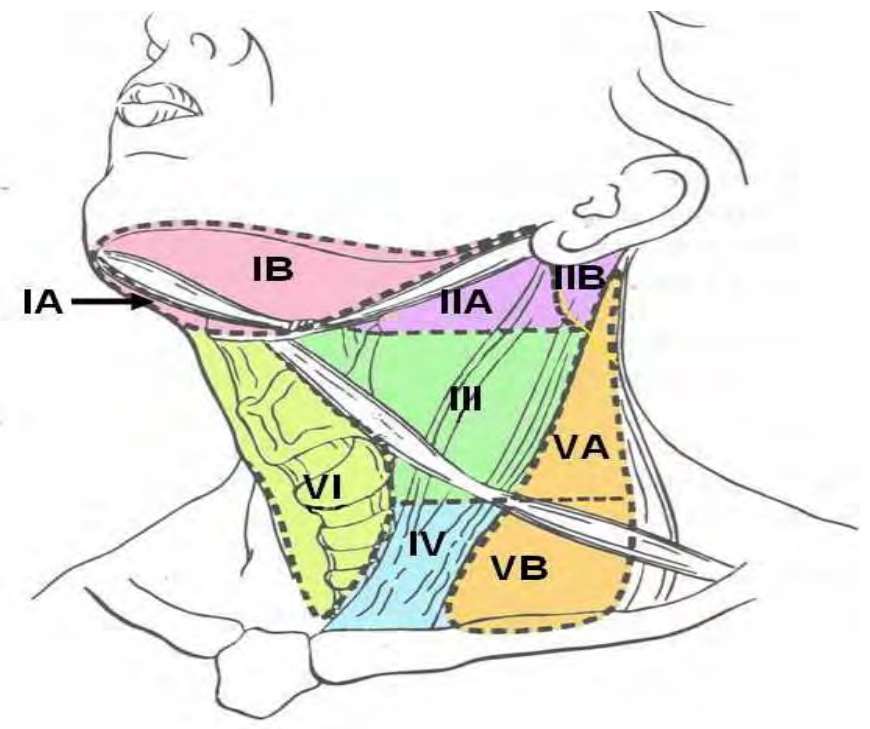




\section{Grey Ultra Sound Scale}

\begin{tabular}{|l|l|}
\hline Size & $\begin{array}{l}\text { The largernodes tend to have a higher incidence of malignancy (reactive } \\
\text { nodes can be as large as metastatic nodes), }\end{array}$ \\
\hline Shape & $\begin{array}{l}\text { Metastatic nodes tend to be round with a short to long axes ratio greater } \\
\text { than 0.5, while reactive or benign lymph nodes are elliptical in shape, }\end{array}$ \\
\hline Borders & $\begin{array}{l}\text { Metastatic lymph nodes tend to have sharp borders whilst benign lymph } \\
\text { nodes usually show un-sharp borders (metastatic nodes with extra cellular } \\
\text { spread may demonstrate ill-defined borders), }\end{array}$ \\
\hline Echogenecity & $\begin{array}{l}\text { Metastatic lymph nodes are predominantly hypoechoic relative to the } \\
\text { adjacent musculature, (metastatic nodes from papillary carcinoma of the } \\
\text { thyroid are usually hyperechoic), }\end{array}$ \\
\hline Necrosis & Intranodal necrosis may be found in metastatic and tuberculosis nodes, \\
\hline Calcification & $\begin{array}{l}\text { Metastatic cervical nodes from papillary carcinoma of the thyroid tend to } \\
\text { show calcification. }\end{array}$ \\
\hline
\end{tabular}

\section{DISCUSSION}

Cervical lymphadenopathy is a manifestation of a spectrum of diseases ranging from infective process to malignant diseases, thereby invasive diagnostics procedure are required to reach to the proper diagnosis ${ }^{10}$. In most of the studies, the most common diagnosis in adults was malignancy while in children infections and benign masses were common.Although infectious causes of lymphadenopathy are more prevalent in the pediatric population compared with adults, neoplasms should also be considered. ${ }^{11}$ Imaging studies, like ultrasound, can provide valuable information for accurate diagnosis. ${ }^{12}$ Fine needle aspiration cytology (FNAC) of lymph nodes is a simple and cost effective, out-patient procedure used for diagnosis of various causes of lymphadenopathy, without serious complications. Overall fine needle aspiration cytology accurately predicted the histological findings (89\%) with a sensitivity of $93.1 \%$, specificity of $100 \% .^{13}$ In our study tuberculous cervical lymphadenopthy was the most common histological diagnosis in 141/270 (52.2\%) patients followed by reactive hyperplasia in 50/270 (18.5\%), lymphoma 33/270 (12.2\%), metastatic $29 / 270$ (10.7\%), Kawasaki disease In Uganda the major causes of cervical lymphadenopathy were: tuberculosis $(69.4 \%)$, Kaposi's sarcoma-KS (10.2\%) and reactive adenitis (7.4\%). ${ }^{14}$ Our study also found very similar findings to a study conducted in Kathmandu ${ }^{15}$. Lymphadenopathy in HIVIAIDS patients may reflect a serious condition, most likely tuberculosis and lymphoma. Since patients might underestimate lymphadenopathy, physicians would rather list these entities for diagnosis. ${ }^{16}$

In a study at University Medical Center Homburg/Saar, the distribution of the most common pathological conditions was as follows: Non-specific reactive hyperplasia $(35.5 \%)$, metastases (34.3\%), lymphoma (16.3\%), granulomatous lesions (6\%), abscess formations (2\%), necrotic lymphadenitis and Castleman's disease one case of each. ${ }^{17}$ In a study in Kolkata, tuberculous lymphadenitis was the most common finding (46.7\%), while reactive hyperplasia $(45 \%)$ in patients less than 20 years of age. Malignant pathology accounted for $13.7 \%$ of cervical lymph node enlargement, most of which was due to metastatic squamous cell carcinoma $(67.7 \%) .{ }^{18}$

\section{CONCLUSION}

$>$ In children, usually cervical lymphadenopathy is reactive or infective while in older age mostly metastatic.

$>$ Tuberculosis is still the commonest cause of cervical lymph node enlargement in our setting in Pakistan, usually involving multiple lymph nodes.

$>$ Lymph node excision biopsy is a well-established diagnostic procedure practiced worldwide. 


\section{REFERENCES}

1. Kerawala C, Newlands C (editors) (2010). Oral and maxillofacial surgery. Oxford: Oxford University Press. pp. 68,377,392-394.

2. Nwawka OK, Nadgir R, Fujita A, Sakai O. Granulomatous disease in the head and neck: developing a differential diagnosis.Radiographics. 2014 Sep-Oct;34(5):1240-56.

3. Kaparos N1, Favrat B, D'Acremont V. [Fever and lymphadenopathy: acute toxoplasmosis in an immunocompetent patient]. Rev Med Suisse. 2014 Nov 26;10(452):2264, 2266-8, 2270.

4. Terézhalmy GT, Huber MA, Jones AC; Noujeim M; Sankar V (2009). Physical evaluation in dental practice. Ames, lowa: Wiley-Blackwell. pp. 120-123,160,172.

5. Kalantzis A, Scully C (2005). Oxford handbook of dental patient care, the essential guide to hospital dentistry. (2nd ed.). New York: Oxford University Press. pp. 47,343.

6. Odell EW (Editor) (2010). Clinical problem solving in dentistry (3rd ed.). Edinburgh: Churchill Livingstone. pp. 91-94.

7. Ahuja A, Ying M. Grey-scale sonography in assessment of cervical lymphadenopathy: review of sonographic appearances and features that may help a beginner. Br J Oral Maxillofac Surg. 2000;38:451.

8. Pindiga UH, Dogo D, Yawe T. Histopathology of primary peripheral lymphadenopathy in North Eastern Nigeria. Nig J Surg Res 1999;1:68-71.

9. Pepper C1, Pai I, Hay A, Deery A, Wilson P, Williamson P, Pitkin L. Investigation strategy in the management of metastatic adenocarcinoma of unknown primary presenting as cervical lymphadenopathy.ActaOtolaryngol. 2014 Aug;134(8):838-42.)

10. Zeshan QM, Mehrukh M, Shahid P. Audit of lymph node biopsies in suspected cases of lymphoproliferative malignancies, implications on the tissue diagnosis and patient management. J Pak Med Assoc 2000;50:179-82.

11. Mabedi C, Kendig C, Liomba G, Shores C, Chimzimu F, Kampani C, Krysiak R, Gopal S. Causes of cervical lymphadenopathy at Kamuzu Central Hospital.Malawi Med J. 2014 Mar;26(1):16-9.

12. Chand P, Dogra R, Chauhan N, Gupta R, Khare P. Cytopathological Pattern of Tubercular Lymphadenopathy on FNAC: Analysis of 550 Consecutive Cases. J ClinDiagn Res. 2014 Sep;8(9):FC16-9.

13. Malik GA, Rehan TM, Bhatti SZ, Riaz JM, Hameed S. Relative frequency of different diseases in patients with lymphadenopathy. Pak J Surg 2003;19;86-9.

14. Maharjan M, Hirachan S, Kafle PK, Bista M, Shrestha S, Toran KC, et al. Incidence of tuberculosis in enlarged neck nodes, our experience. Kathmandu Univ Med J 2009;7:54-8.

15. Muyanja D, Kalyesubula R, Namukwaya E, Othieno E, Mayanja-Kizza H. Diagnostic accuracy of fine needle aspiration cytology in providing a diagnosis of cervical lymphadenopathy among HIV-infected patients.Afr Health Sci. 2015 Mar;15(1):107-16.

16. Hadadi A, Jafari S, Jebeli ZH, Hamidian R. Frequncy and etiology of lymphadenopathy in Iranian HIVIAIDS patients. Asian Pac J Trop Biomed. 2014 May;4(Suppl 1):S171-6.

17. Mitra S, Ray S, Mitra PK. Analysis of FNAC of cervical lymph nodes: experience over a threeyear period. J Indian Med Assoc. 2013 Sep;111(9):599-602.

18. Umer MF, Mehdi SH, Muttaqi A, Hussain SA. Presentation and aetiological aspects of cervical lymphadenopathy at Jinnah Medical College Hospital Korangi Karachi. Pak J Surg 2009; 25:224-6. 